Research Article

\title{
Nonzero Staircase Modulation Scheme for Switching DC-DC Boost Converter
}

\author{
Ayodeji Olalekan Salau $\mathbb{D}^{1},{ }^{1}$ Candidus U. Eya, ${ }^{2}$ and Omeje Crescent Onyebuchi ${ }^{3}$ \\ ${ }^{1}$ Department of Electrical/Electronics and Computer Engineering, Afe Babalola University, Ado-Ekiti, Nigeria \\ ${ }^{2}$ Department of Electrical Engineering, University of Nigeria, Nsukka, Enugu State, Nigeria \\ ${ }^{3}$ Department of Electrical and Electronics Engineering, University of Port Harcourt, Port Harcourt, Nigeria
}

Correspondence should be addressed to Ayodeji Olalekan Salau; ayodejisalau98@gmail.com

Received 12 January 2020; Revised 24 May 2020; Accepted 2 June 2020; Published 18 July 2020

Academic Editor: Hassan Haes Alhelou

Copyright $(2020$ Ayodeji Olalekan Salau et al. This is an open access article distributed under the Creative Commons Attribution License, which permits unrestricted use, distribution, and reproduction in any medium, provided the original work is properly cited.

\begin{abstract}
This paper presents a novel modulation scheme known as the nonzero staircase modulation scheme for switching DC-DC boost converters. This modulation scheme generates two distinct pulse trains/firing signals when a $50 \mathrm{~Hz}$ nonzero staircase modulating signal is compared with a $1.5 \mathrm{kHz}$ triangular wave signal. Unlike the conventional modulation schemes, the proposed novel modulation scheme provides two distinctive trains of pulse-width modulated signals for mitigating low and high harmonics. It also possesses $0.56 \%$ total harmonic distortions (THD) of the output voltage waveform system, a power output of $4591 \mathrm{~W}$, and THD of $1.12 \%$ in the DC-DC boost converter system. It has a simple design and low power loss of $209 \mathrm{~W}$. The proposed scheme enables the single switch boost DC-DC converter used to have an efficiency of $96 \%$. The proposed scheme can be applied in single switch or double switch boost DC-DC converter based-hospital equipment.
\end{abstract}

\section{Introduction}

The DC-DC boost converter is a power electronic converter that is placed most especially between a low unregulated voltage power source and a load. Its key function is to step up low voltage power sources to suit the needed application. Some areas of application of DC-DC boost converters are in DC microgrid systems, pulsed lasers, electric trains, X-rays, uninterruptible power systems, inverters, satellites, and wireless power transfers [1]. In the course of its application, it can change an unregulated fixed voltage as in the case of a battery or variable voltage to a controlled variable output voltage depending on the level of the duty cycle (D) [2]. Its input voltage sources could be obtained from solar power supplies, rectified AC voltage supplies, battery, fuel cells, biomass, and supercapacitors [3]. It consists of three nonstorage elements (power electronic switch, freewheeling diode, and power diode), and two storage elements, inductor and capacitor. The DC-DC boost converter can operate both in continuous current mode (CCM) and discontinuous current mode (DCM) based on its area of application.
In switched mode condition, power is transferred from the source to the load by triggering power electronic switches such as MOSFETs or IGBTs. A number of works have been presented on different modulation schemes used in firing different DC-DC boost converters $[4,5]$. Some of them are Single pulse-width modulation, multiple pulsewidth modulation (MPWM), DC/triangular compared modulation scheme, square-wave modulation, and many others with their merits and demerits $[6,7]$. In single pulsewidth modulation, there is only one pulse in each half cycle and the width of the pulse is varied to control the output voltage of the converter. Moreover, in this type of PWM scheme, a carrier signal is compared with a square reference wave. The frequency of the carrier is twice the frequency of the reference signal. The triangular wave has a constant amplitude and the square reference wave has a variable amplitude, so that the width of the pulse can be varied to eliminate low harmonic distortion. The major demerit of this scheme is that as the pulse width increases, it contributes heavily to switching losses, increases the harmonic content, and decreases efficiency. In MPWM, many pulses of the 
same width are produced in each half cycle and the greater harmonic contents can be reduced unlike in the single pulsewidth modulation. In a square-wave modulation, one pulse is generated in one-half cycle with a width of $50 \%$ of the full cycle. This is formed when a reference sine wave is compared with a zero input potential voltage. It only reduces the low harmonic distortions and pushes the high harmonic distortions to large discrete output filter components. This also increases the cost of production, weight, and the volume of the system.

A conventional staircase modulation scheme as presented in [8] was applied in controlling a hybrid multilevel inverter topology with a reduced number of power electronic components. In [9], another zero crossing digital staircase pulse modulator was used in maximizing the fundamental component and eliminating certain low harmonics in DC/AC converters. Apart from considering only low harmonics, a complex computational analysis was also analysed.

In this paper, a novel modulation scheme known as nonzero staircase modulation scheme with simplified analysis for switching DC-DC boost converters is proposed. It has two distinctive trains of pulse width features for mitigating both low and high harmonic distortions (total harmonic distortion) for power loss reduction in power electronic systems. The proposed modulation scheme is used for single-switched PWM DC-DC boost converters but can also be applied in double-switched DC-DC converters.

The major advantages of the proposed scheme are as follows: (i) it minimizes the cost of using high system filter components since it has the capability of mitigating both low and high harmonics. (ii) It enables the DC-DC boost converter system to experience low power losses. (iii) It increases the quality of output power due to its low total harmonics distortions. (iv) It has a simple design. (v) It assists the DC-DC converter in operating in a continuous current mode. (vi) It enhances high power system efficiency.

\section{Single-/Double-Switched DC-DC Converter Modulation Schemes}

The efficiency enhancement of DC-DC boost converters by parallel switch correlation (connection) was carried out by the authors in [10]. The single switch used in their work is triggered by a uniform $25 \mathrm{kHz}$ pulse. The $25 \mathrm{kHz}$ firing pulse was obtained with the aid of an Arduino UNO microcontroller which achieved a conversion efficiency of $70 \%$. However, the uniform pulses generated can only minimize low harmonics. Many DC-DC converter topologies were reviewed by authors in [11] based on their different degrees of efficiencies. Meanwhile, only circuit configuration modulation schemes which also contribute greatly to the efficiency of DC-DC converters were not considered by the authors in their work.

Therefore, considering the modulation techniques used in single switch DC-DC converters/double switch DC-DC converters, the most common ones used are DC voltage compared with Sawtooth modulation scheme (DCVCSM)/ chaotic frequency modulation [12], DC voltage-triangular based modulation scheme (DCVTBM), zero potential compared sinewave modulation scheme (ZPCSMS), rectified-triangular modulation scheme (RTMS), and sliding window-based pulse-width modulation (SWBPWM) [13-18]. RTMS can also be applied in a converter with more than one switch converter [19].

A rectified-triangular modulation scheme (RTMS) is presented in Figure 1(a). It produces the pulses in Figure 1(b), while Figure 1(c) illustrates the power output and its spectral analysis. A power output of $2928 \mathrm{~W}$, total harmonic distortion (THD) of $9.79 \%$, and a modulation index of 0.9 was realized using the RTMS technique on the boost DC-DC converter in Figure 2.

The DC-voltage compared with Sawtooth modulation (DCVCSM) scheme is shown in Figure 3(a). The pulses generated by comparing DC voltage and Sawtooth signal (ZPCSMS) is shown in Figure 3(b), while Figure 3(c) shows the spectral analysis of output power of the boost DC-DC converter using DCVCSM.

The DCVTBM technique and its generated triggering pulses are shown in Figures 4(a) and 4(b). The harmonic analysis of the power output of the boost DC-DC converter using DCVTBM is presented in Figure 4(c). It can be seen that Figure 4(c) contains a DC output power and THD of $4204 \mathrm{~W}$ and $4.65 \%$, respectively. The DCVTBM possesses a modulation index of 0.9 .

A sinusoidal reference voltage is compared with a zero potential difference as shown in Figure 5(a). This produces the switching pulses in Figure 5(b). The pulses generated were used to switch the circuit in Figure 2 in order to generate the DC power output waveform shown in Figure 5(c). From the spectral analysis illustrated in Figure 5(c), it is observed that a DC power output and THD of $2229 \mathrm{~W}$ and $33.74 \%$ was achieved, respectively.

\section{Principle and Design Method for Generating the Nonzero Staircase Modulation}

The nonzero staircase modulation scheme is a type of modulation scheme that generates two distinct pulse trains/ firing signals when a nonzero staircase modulating signal is compared with a triangular wave signal. In this type of modulation technique, the wider section of the generated pulses reduces the low order harmonics, while the narrower region minimizes the higher-order harmonics. The number of the nonzero staircase modulating signal has ascending and descending regions. The descending region is a mirror image of the ascending region. The height of the modulating signal is equivalent to the amplitude of the voltage signal. Overmodulation occurs when the nonzero staircase reference is greater than the carrier wave. Therefore, the modulating nonzero staircase signal should be less than the carrier wave.

To design this, a mode of half-sine wave is needed to be partitioned into equal parts following other designer's considerations. In this work, a mode of half-sine wave was partitioned into twenty equal parts with time scales. The peak at each point is relative to the switching angle at that position. In order to actualize the nonzero position of the 
proposed staircase scheme, the zero angle and $180^{\circ}$ are not used in the design. In addition, an offset level, $h_{\mathrm{o}}$ is chosen. The key idea here is to ensure complete avoidance of discontinuous current mode and to accomplish high harmonic reduction (in either low and high order harmonics or total harmonic reductions). The total number, $N$, of the proposed system should be an even number. The height of the nonzero staircase is equivalent to the signal voltage. The proposed schemes design is presented in Figure 6.

In Figure 6, it is observed that the heights of staircase reference from $h_{11}$ to $h_{20}$ are the mirror images from $h_{1}$ to $h_{10}$. This simply means that $h_{1}=h_{11}, h_{2}=h_{12}, h_{3}=h_{13}, h_{4}=h_{14}$, $h_{5}=h_{15}, h_{6}=h_{16}, h_{7}=h_{17}, h_{8}=h_{16}, h_{9}=h_{19}$, and $h_{10}=h_{20}$.

The switching angles, $\theta_{i}$, for 20 steps of the staircase are calculated using the formula in equation (1) and the results are presented in Table 1.

$$
\theta_{i}=\frac{J \times 180}{2 N},
$$

where $J$ is an odd number, i.e., $1,3,5,7,9,11,13,15,17,19$, and $N$ is the total number of steps. $i=1,2,3,4,5,6, \ldots 20$.

3.1. Computation of Switching Angles. Using equation (1), where $N$ is 20 , Table 1 is obtained.

For $i=1$ and $J=1, \theta_{1}$ is obtained as $\theta_{1}=(1 \times 180) /$ $(2 \times 20)=4.5^{\circ}$.

The height of each staircase signal from the zero-axis is $H_{i}$ and is determined using the following equation:

$$
H_{i}=A_{p} \cos \left(\theta_{i}-90\right) \text {, }
$$

where $i=1,2,3, \ldots \ldots \ldots 20$.

3.2. Computation of Heights of Staircase Modulating Reference Signal from Zero X-Axis. The heights of staircase modulating Reference Signal from Zero X-axis; $H_{i}$ are computed using equation (2) as follows:

$$
H_{i}=A_{p} \cos \left(\theta_{i}-90\right),
$$

For $i=1$ and using the calculated value of $\theta_{1}=4.5^{\circ}$, assuming $A_{p}=10 \mathrm{~m}$ throughout the process, then

$$
H_{1}=10 \cos (4.5-90)=0.78 \mathrm{~m} \text {. }
$$

The remaining heights of the staircase modulating reference signal from the zero-axis were computed and are presented in Table 2.

The height of each staircase signal from the nonzero-axis is $h_{i}$ and is calculated using

$$
h_{i}=\left[A_{p} \cos \left(\theta_{i}-90\right)\right]-h_{o}=H_{i}-h_{o} .
$$

\subsection{Computation of Heights of Nonstaircase Modulating} Reference. The offset, $h_{o}$, is assumed to be $0.05 \mathrm{~m}$ throughout the calculation of $h_{i}$. Therefore, for $H_{1}=0.78 \mathrm{~m}$ as calculated, and $h_{o}=0.05 \mathrm{~m}$,

$$
h_{1}=0.78-0.05=0.73 \mathrm{~m} .
$$

The other heights of the nonstaircase modulating reference signal were obtained and are presented in Table 3.

Having computed $h_{1}, h_{2}, h_{3}, h_{4}, h_{5}, h_{6}, h_{7}, h_{8}, h_{9}$, and $h_{10}$ of the nonzero staircase modulation scheme, we obtain $h_{11}$, $h_{12}, h_{13}, h_{14}, h_{15}, h_{16}, h_{17}, h_{18}, h_{19}$, and $h_{20}$ as the mirror images of $h_{1}, h_{2}, h_{3}, h_{4}, h_{5}, h_{6}, h_{7}, h_{8}, h_{9}$, and $h_{10}$.

The complete computed results of equations (1), (2), and (5) for the generating nonzero staircase reference signal with their $\Theta_{i}, H_{i}$, and $h_{i}$ mirror image values which were used in MATLAB/Simulink modulating block shown in Figure 7 are presented in Table 4.

The carrier signal is generated in Matlab/Simulink using the following equation:

$$
C_{r}=\left[\begin{array}{ccc}
\frac{1}{f_{c}}-\frac{1}{f_{c}} & \frac{1}{2 f_{c}} & \frac{1}{f_{c}} \\
y-M & y & y-M
\end{array}\right],
$$

where $C_{r}$ is the carrier signal, $f_{c}$ is the carrier frequency, $y$ is the amplitude of the carrier wave, and $M$ is an integer. In equation (7), " $y$ " must be equal to " $M$ " in magnitude. In order to produce the triggering signals with two distinctive pulse trains for firing the IGBT switch connected in the DCDC boost converter, equation (2) is compared with equation (5).

The values of the storage elements $L$ and C of the DC-DC boost converter are computed using equations (8) and (9) as given in [2].

$$
\begin{gathered}
L_{\min }=\frac{D(1-D)^{2} R}{2 f_{c}}, \\
C_{\min }=\frac{D}{R\left(\Delta V_{o} / V\right) f_{c}} .
\end{gathered}
$$

$L_{\min }, C_{\min }, V_{\mathrm{o}}$, and $R$ are the minimum capacitance, minimum inductance, output voltage, and output load resistance of the converter.

\section{The Feedback Control System}

4.1. Circuit Diagram of the PI Controller. In the feedback control unit, the proportional-plus-integral controller is utilized [10-12]. The circuit diagram is shown in Figure 8 [20-22]. The figure shows the circuit diagram of the PI controller with the following components, sensed voltage, $V_{\text {sensed }}$, DC referenced voltage, $V_{r e f 1}$, error voltage (input voltage to the PI controller), $V_{e}$, resistances, $R_{1}, R_{2}, R_{3}, R_{4}$, $R_{5}$ and feedback capacitance, $C$.

The transfer function of the PI controller in Figure 8 is expressed as follows [23]:

$$
T(s)=\frac{V_{\text {out }}}{V_{e}}=K_{p}+\frac{K_{i}}{s} .
$$

4.2. Tuning Principle of the PI Controller. The PI controller is tuned or adjusted based on the level of the output voltage across the load connected to the DC-DC boost converter. 


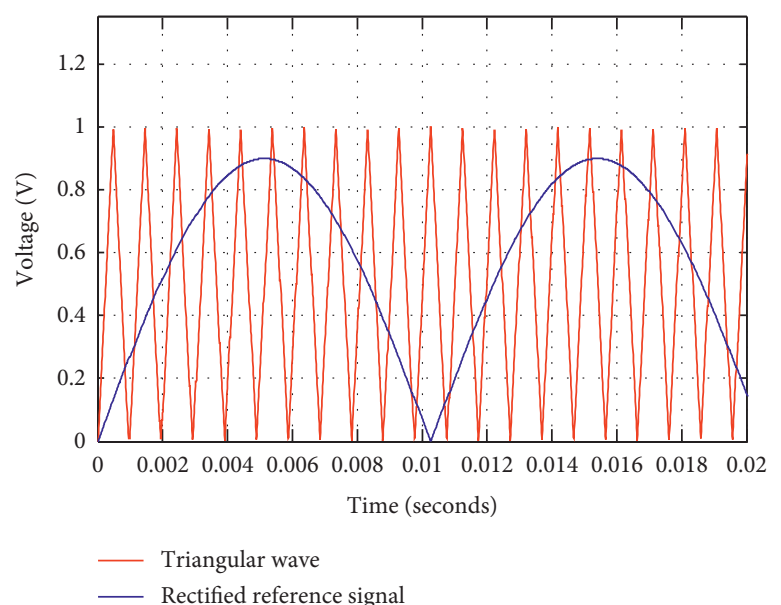

(a)

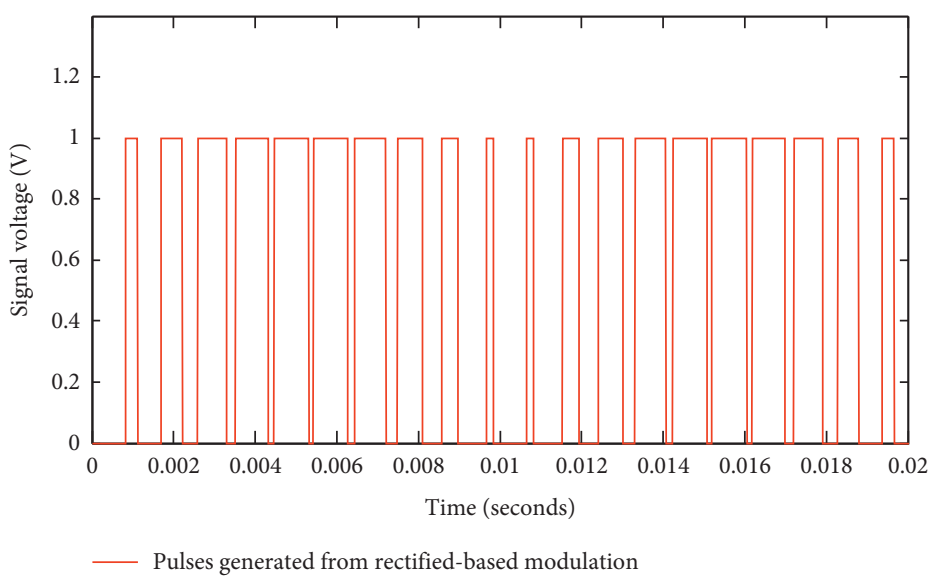

(b)
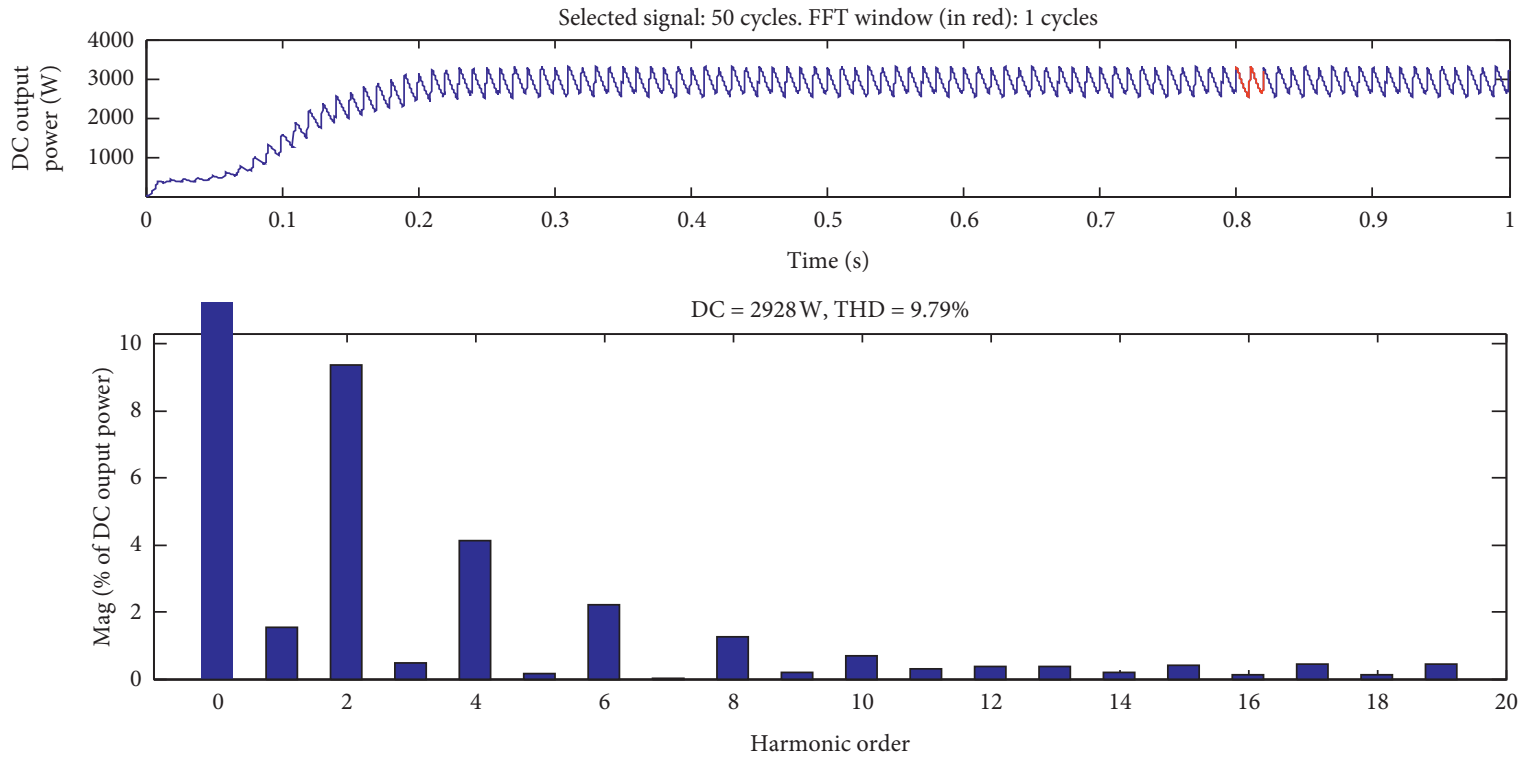

(c)

Figure 1: (a) RTMS. (b) Firing pulses of RTMS. (c) Spectral analysis of the output power of boost DC-DC converter using RTMS.

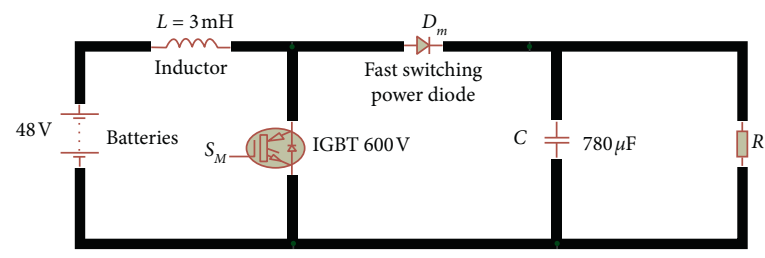

FIgURE 2: Proteus Circuit of DC-DC boost converter [13].

This was done to keep the output voltage constant. The PI tuning principle is stated as follows:

$$
V_{e}= \begin{cases}V_{\text {sensed }}-V_{\text {ref } 1}, & \text { when } V_{\text {sensed }}>V_{\text {ref } 1} \text {, then PI decreases the } W 1 \text { and } W 2 \text { in Figure } 9(\mathrm{~b}), \\ V_{\text {ref } 1}-V_{\text {sensed }}, & \text { when } V_{\text {sensed }}<V_{\text {ref } 1} \text {, then PI increases the } W 1 \text { and } W 2 \text { in Figure } 9(\mathrm{~b}), \\ 0, & \text { when } V_{\text {sensed }}=V_{\text {ref } 1} \text {, then } W 1 \text { and } W 2 \text { in Figure } 9(\mathrm{~b}) \text { remain constant. }\end{cases}
$$




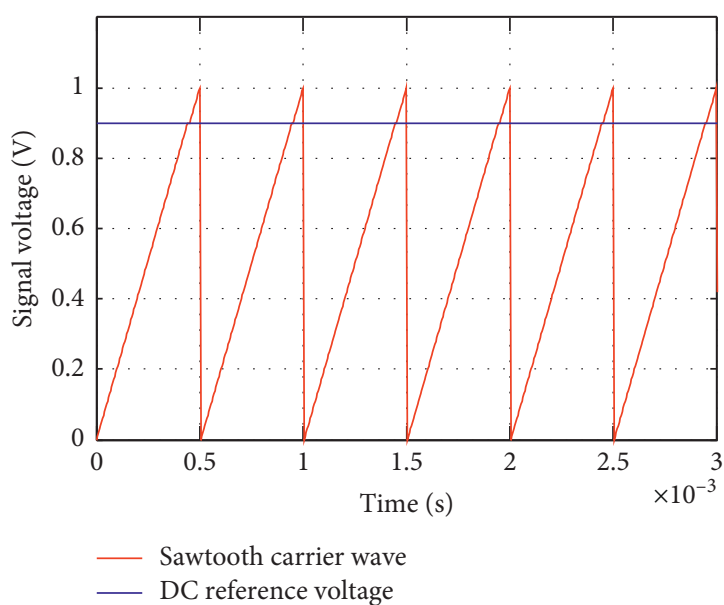

(a)

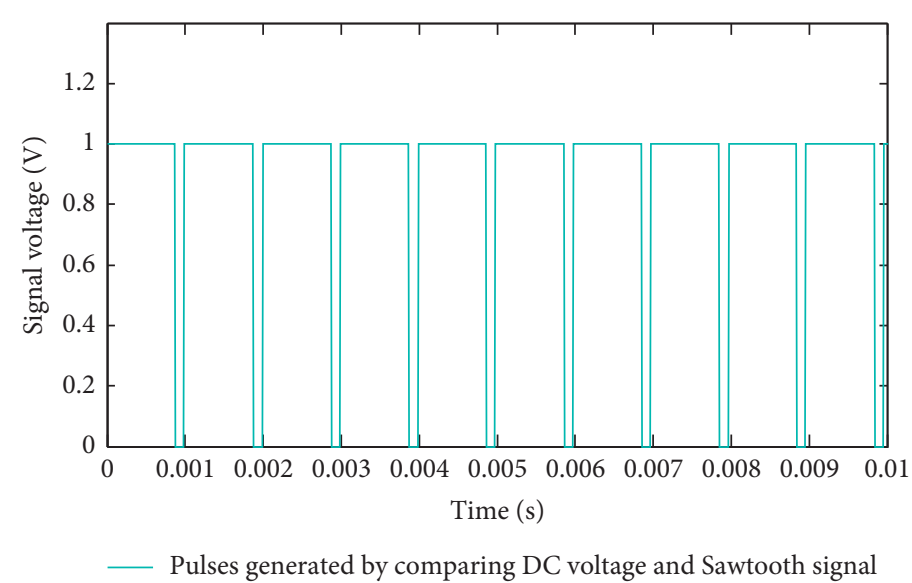

(b)
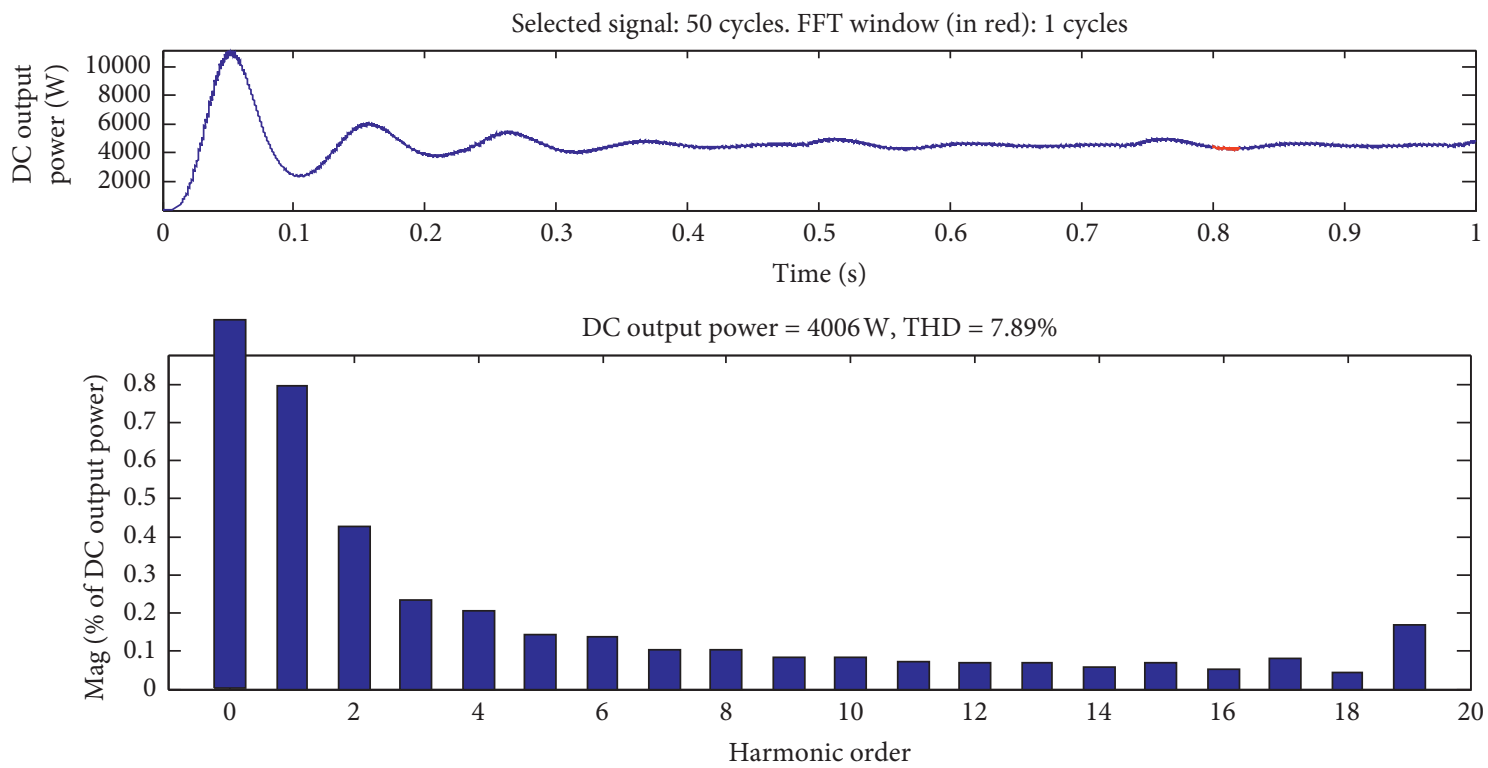

(c)

Figure 3: (a) DCVCSM. (b) Firing pulses of ZPCSMS. (c) Spectral analysis of the output power of boost DC-DC converter using DCVCSM.

When the sensed voltage is greater than the DC reference voltage, it means that the output voltage at that point in time is greater than the desired output voltage of the system; then, the error voltage goes into the PI controller. Immediately after this, the current will flow from the capacitor, $C$, to $V_{r e f 1}$ through $R_{5}, R_{3}$, and $R_{2}$ to discharge the capacitor. As the capacitor, $C$, discharges, the width of switching signals, $W 1$ and $W 2$ are reduced to bring back the output voltage to the desired output voltage level. On the other hand, if the sensed voltage is lower than the DC reference voltage, it means that the output voltage at that moment is lower than the desired output voltage of the system; then, the error voltage goes into the PI controller to increase the width of switching signals, $W 1$ and $W 2$, making the power switch to operate faster. During this period, the current flows from $V_{\text {ref } 1}$ to charge the capacitor through $R_{2}, R_{3}$, and $R_{5}$. Furthermore, if $V_{\text {sensed }}$ is equal to $V_{\text {ref } 1}$, the error voltage becomes zero. When no current flows into or out of the PI controller, the voltage across the capacitor, $C$, clamps the widths of the pulses. At this point, the output voltage across the load becomes stabilized. The electrical interactions of $V_{e}, V_{\text {out }}, R_{2}, R_{3}, C$, and $R_{5}$ produce the proportional constant, $K_{p}$, and integral constant, $K_{i}$ that controls the switching action in order to stabilize the output voltage of the system.

\subsection{Determination and Computation of Proportional Con-} stant and Integral Constant of the PI Controller. The proportional and integral terms $K_{p}$ and $K_{i}$ used in this work are deduced as follows:

Considering the inverting terminal of the operational amplifier in Figure 8 and applying the Kirchhoff's current law, the current entering node $L$ is equal to the current leaving it; therefore,

$$
\frac{V_{e}-V_{L}}{R_{3}}=\frac{V_{L}-V_{\text {out }}}{R_{5}+Z_{C}}
$$




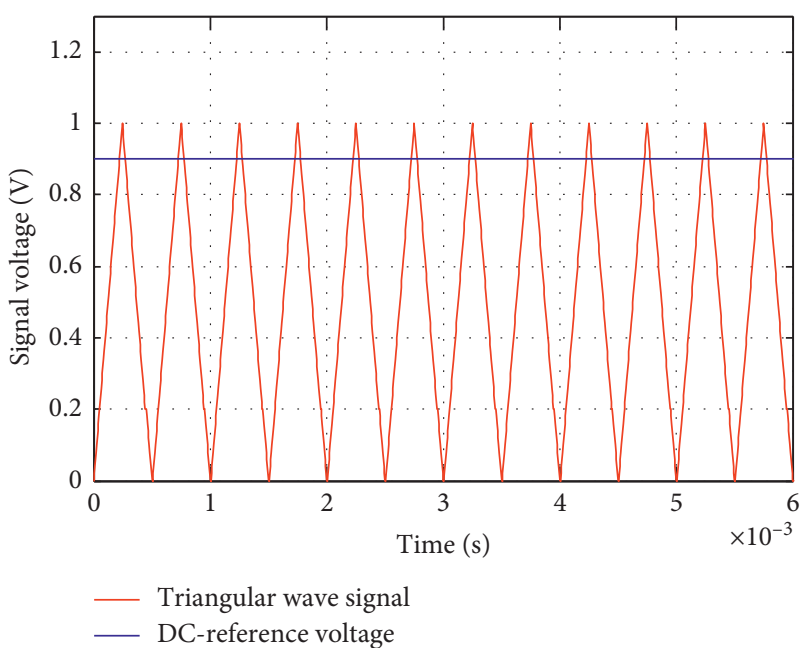

(a)

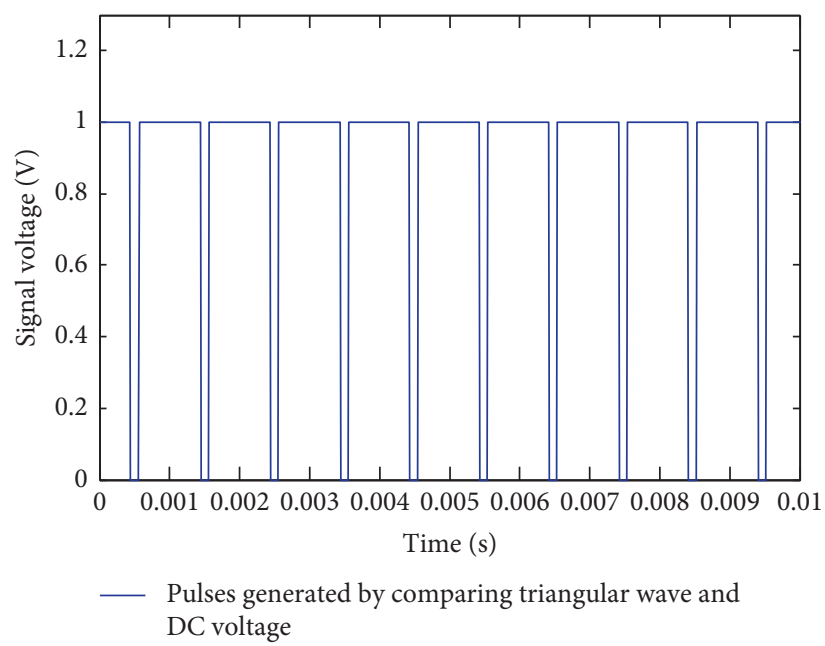

(b)
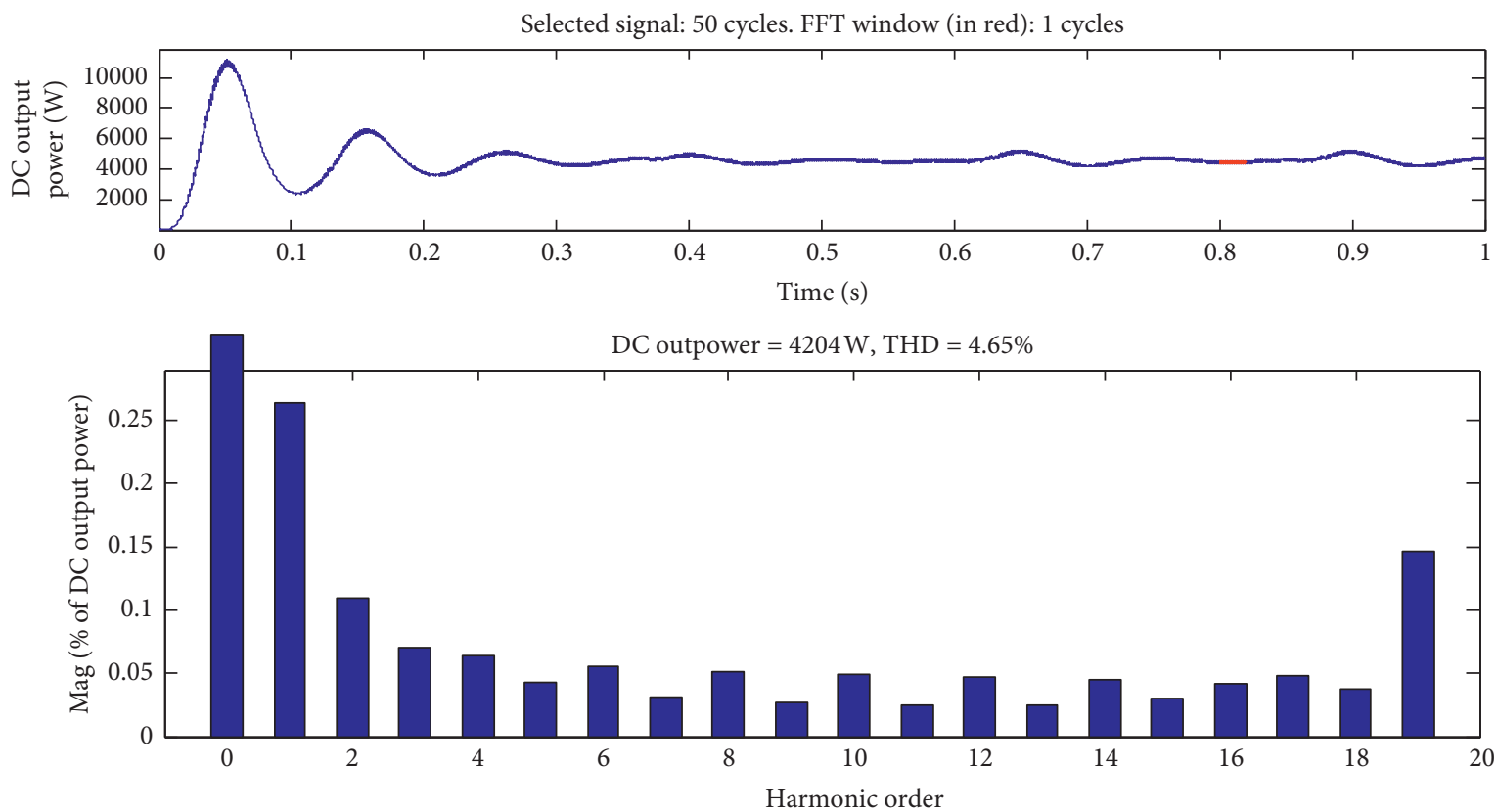

(c)

Figure 4: (a) DCVTBM. (b) Firing pulses of ZPCSMS. (c) Spectral analysis of the output power of boost DC-DC converter using DCVTBM.

where $V_{L}$ and $Z_{C}$ are the inverting terminal voltage and capacitive impedance, respectively. Therefore, by rearranging equation (12) to make $V_{L}$ the subject of the formula, equation (13) is obtained.

$$
V_{L}=\frac{V_{e} R_{5}+V_{e} Z_{C}+R_{3} V_{\text {out }}}{R_{3}} .
$$

Furthermore, considering the noninverting terminal and node, $m$, the noninverting voltage becomes

$$
V_{m}=0 \text {. }
$$

Then, equating equations (13) and (14), and getting the ratio of $V_{\text {out }}$ to $V_{e}$ of the PI controller and taking its absolute expression, equations (15) and (16) become

$$
\begin{aligned}
\left|-\frac{V_{\text {out }}}{V_{e}}\right| & =\left|\frac{R_{5}+Z_{C}}{R_{3}}=\frac{R_{5}}{R_{3}}+\frac{Z_{C}}{R_{3}}\right|, \\
\frac{V_{\text {out }}}{V_{e}} & =\frac{R_{5}}{R_{3}}+\frac{1}{R_{3} C s} .
\end{aligned}
$$

Subsequently, comparing equations (10) and (16), the $K_{p}$ and $K_{i}$ becomes 


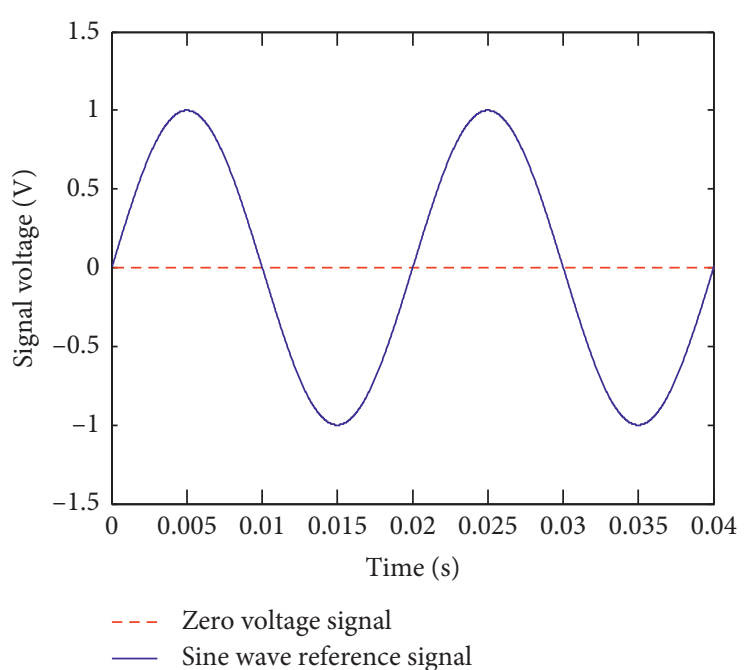

(a)

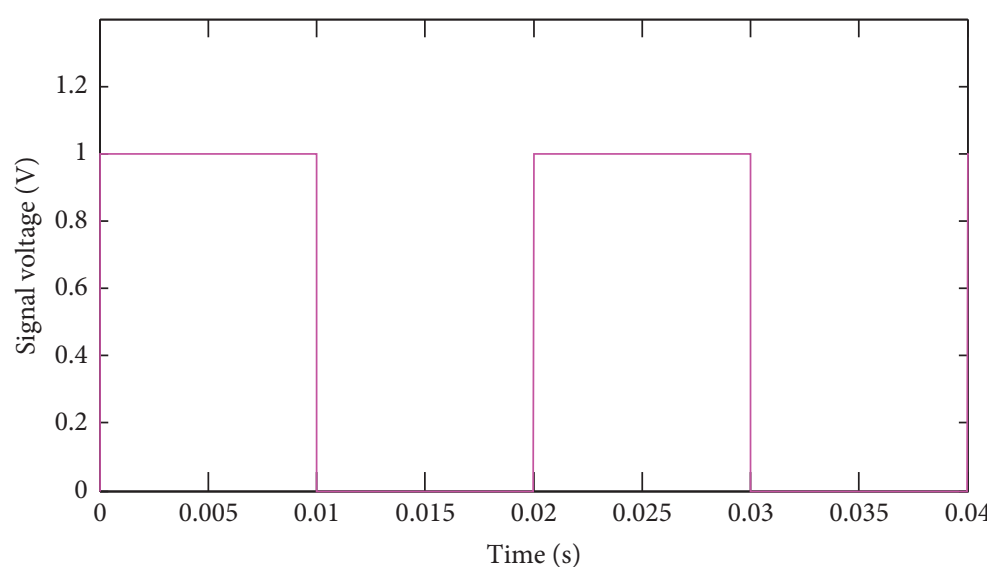

__ Pulses generated by comparing zero voltage and sinusoidal wave signal

(b)
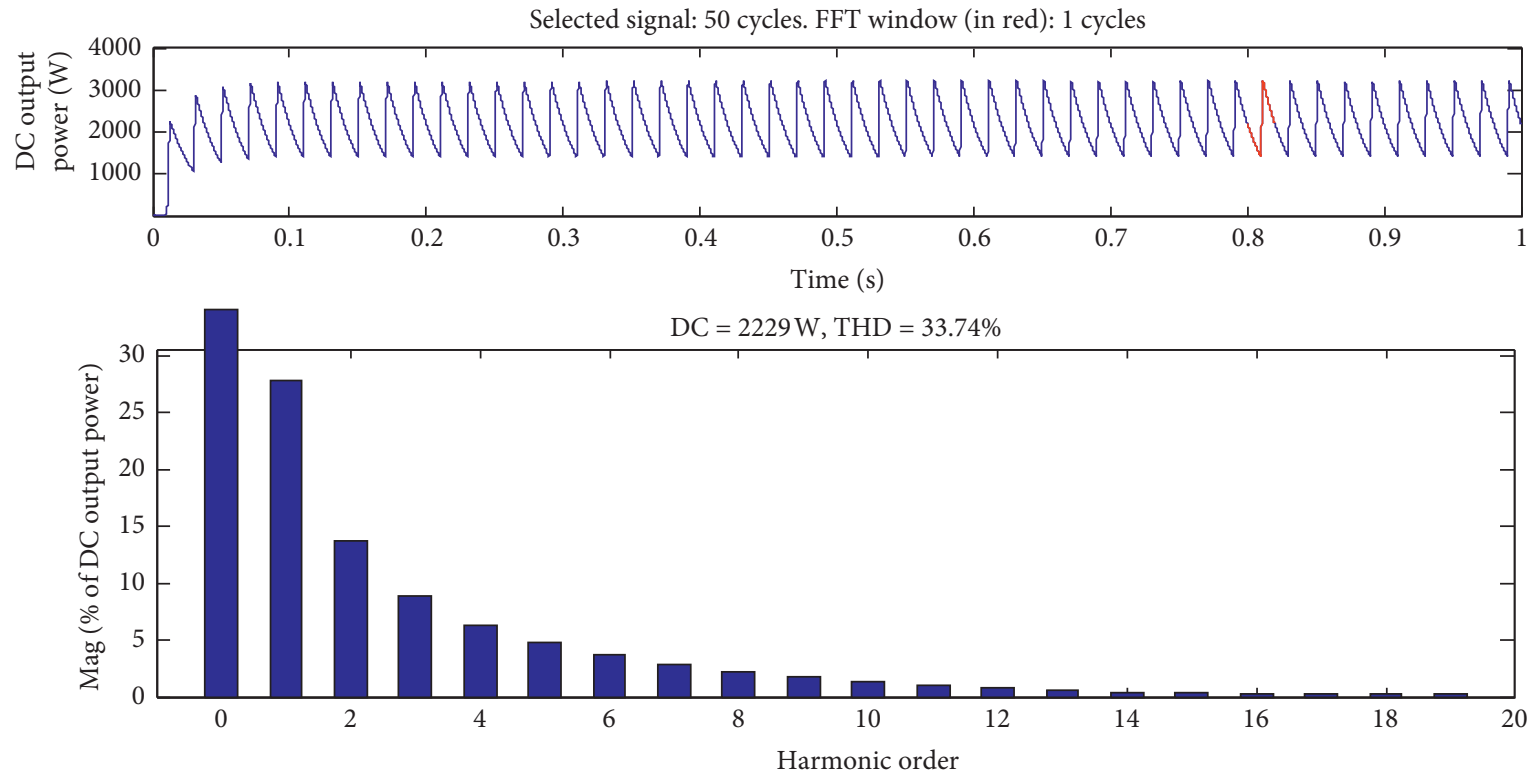

(c)

Figure 5: (a) ZPCSMS. (b) Firing pulses of ZPCSMS. (c) Spectral analysis of the output power of boost DC-DC converter using ZPCSMS.

$$
\begin{aligned}
& K_{p}=\frac{R_{5}}{R_{3}}, \\
& K_{i}=\frac{1}{R_{3} C} .
\end{aligned}
$$

Moreover, the time constant for charging and discharging the feedback capacitor in Figure 8 is expressed by the following equation:

$$
\tau=R_{3} C,
$$

where $\tau$ is the time constant for charging and discharging, $C$. Assuming that $R_{5}=R_{3}=10 \mathrm{k} \Omega$, and $\tau=1.74$ seconds. Substituting the values of $R_{3}$ and $\tau$ in equation (19), then, $C$ becomes $174 \mu \mathrm{F}$. Then substituting the values of $C$ and $R_{3}$ in equation (18), $K_{i}$ becomes 0.57 . When the values of $R_{3}$ and $R_{5}$ are substituted in equation (17), $K_{p}$ becomes 1.0 .

\section{Total Harmonic Distortion}

5.1. Computational Formula of Total Harmonic Distortion. The current and voltage of total harmonic distortions (THDs) are computed using the expressions in the following equations $[2,24]$ : 


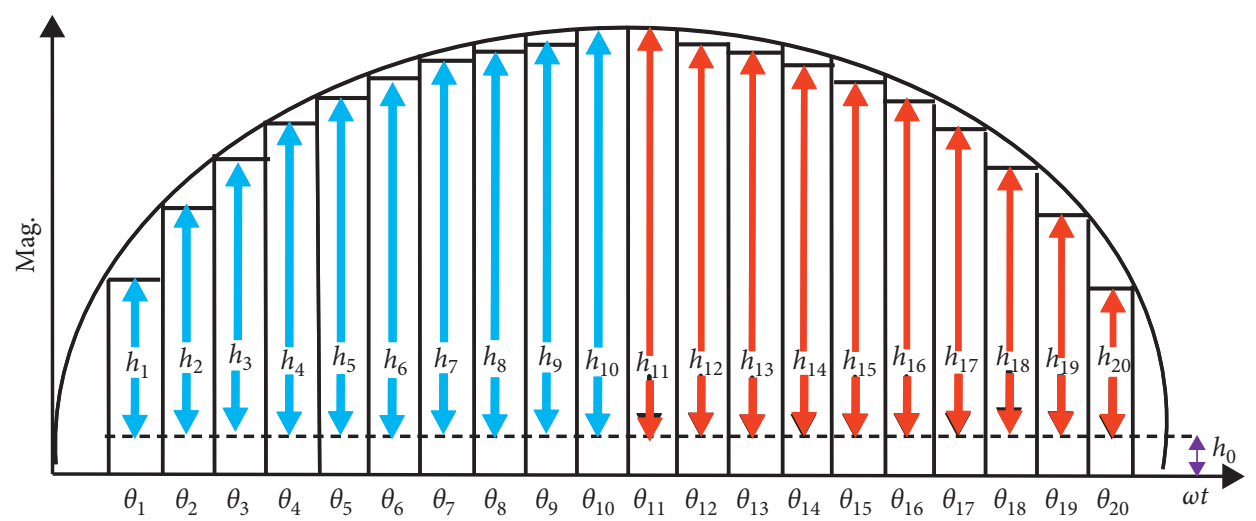

Figure 6: Design scheme for the nonzero staircase reference.

TABLE 1: Calculation of switching angles.

\begin{tabular}{lccc}
\hline$S / n$ & $i$ & $J$ & $\theta$ \\
\hline 1 & 1 & 1 & $\theta_{1}=4.5^{\circ}$ \\
2 & 2 & 3 & $\theta_{2}=13.5^{\circ}$ \\
3 & 3 & 5 & $\theta_{3}=22.5^{\circ}$ \\
4 & 4 & 7 & $\theta_{4}=31.5^{\circ}$ \\
5 & 5 & 9 & $\theta_{5}=40.5^{\circ}$ \\
6 & 6 & 11 & $\theta_{6}=49.5^{\circ}$ \\
7 & 7 & 13 & $\theta_{7}=58.5^{\circ}$ \\
8 & 8 & 15 & $\theta_{8}=67.5^{\circ}$ \\
9 & 9 & 17 & $\theta_{9}=76.5^{\circ}$ \\
10 & 10 & 19 & $\theta_{10}=85.5^{\circ}$ \\
\hline
\end{tabular}

TABLE 2: Calculation of heights of staircase modulating reference signal from zero-axis.

\begin{tabular}{lccc}
\hline$S / n$ & $i$ & $\theta$ & $H_{i}(\mathrm{~m})$ \\
\hline 1 & 1 & $\theta_{1}=4.5^{\circ}$ & $H_{1}=0.78$ \\
2 & 2 & $\theta_{2}=13.5^{\circ}$ & $H_{2}=2.33$ \\
3 & 3 & $\theta_{3}=22.5^{\circ}$ & $H_{3}=3.82$ \\
4 & 4 & $\theta_{4}=31.5^{\circ}$ & $H_{4}=5.22$ \\
5 & 5 & $\theta_{5}=40.5^{\circ}$ & $H_{5}=6.49$ \\
6 & 6 & $\theta_{6}=49.5^{\circ}$ & $H_{6}=7.60$ \\
7 & 7 & $\theta_{7}=58.5^{\circ}$ & $H_{7}=8.53$ \\
8 & 8 & $\theta_{8}=67.5^{\circ}$ & $H_{8}=9.72$ \\
9 & 9 & $\theta_{9}=76.5^{\circ}$ & $H_{9}=9.72$ \\
10 & 10 & $\theta_{10}=85.5^{\circ}$ & $H_{10}=9.96$ \\
\hline
\end{tabular}

$$
\begin{aligned}
& \operatorname{THD}(\text { for current })=\frac{\sqrt{\sum_{n=2}^{\infty} I_{n}^{2}}}{I_{1}}, \\
& \operatorname{THD}(\text { for voltage })=\frac{\sqrt{\sum_{n=2}^{\infty} V_{n}^{2}}}{V_{1}},
\end{aligned}
$$

where $I_{n}$ and $V_{n}$ are amplitude harmonic components of the current, $I_{1}$, and the voltage, $V_{1}$.
TABLE 3: Computation of heights of nonstaircase modulating reference.

\begin{tabular}{lccc}
\hline$S / n$ & $i$ & $H_{i}(\mathrm{~m})$ & $h_{i}(\mathrm{~m})$ \\
\hline 1 & 1 & $H_{1}=0.78$ & $h_{1}=0.73$ \\
2 & 2 & $H_{2}=2.33$ & $h_{2}=2.28$ \\
3 & 3 & $H_{3}=3.82$ & $h_{3}=3.77$ \\
4 & 4 & $H_{4}=5.22$ & $h_{4}=5.17$ \\
5 & 5 & $H_{5}=6.49$ & $h_{5}=6.44$ \\
6 & 6 & $H_{6}=7.60$ & $h_{6}=7.55$ \\
7 & 7 & $H_{7}=8.53$ & $h_{7}=8.03$ \\
8 & 8 & $H_{8}=9.72$ & $h_{8}=9.19$ \\
9 & 9 & $H_{9}=9.72$ & $h_{9}=9.67$ \\
10 & 10 & $H_{10}=9.96$ & $h_{10}=9.92$ \\
\hline
\end{tabular}

The computation of THD current and voltage waveforms using equations (18) and (19) is an approximate method presented in [23]. This method was found to be a very cumbersome, difficult, and time-consuming [23]. Therefore, to save time and get precise values of THD of the system, we employed a tool known as power graphic user interface Fast Fourier Transform, PGUIFFT, or power graphic user interface analysis tool, PGUIAT in Matlab/ Simulink environment, 2014.

\subsection{Steps in Using Power Graphic User Interface Fast Fourier Transform}

Step A: configure the proposed system in the Simulink environment.

Step B: select the PGUIFFTAT from the Simulink library browser.

Step C: double click on workspace block and single click on "parameters" inside the workspace. Then click on "History" and adjust its "Format" in "Structure with time" and click "OK."

Step D: run or simulate the proposed system.

Step E: double click on PGUIFFTAT discrete block, it will display "simulation and configuration Option." 


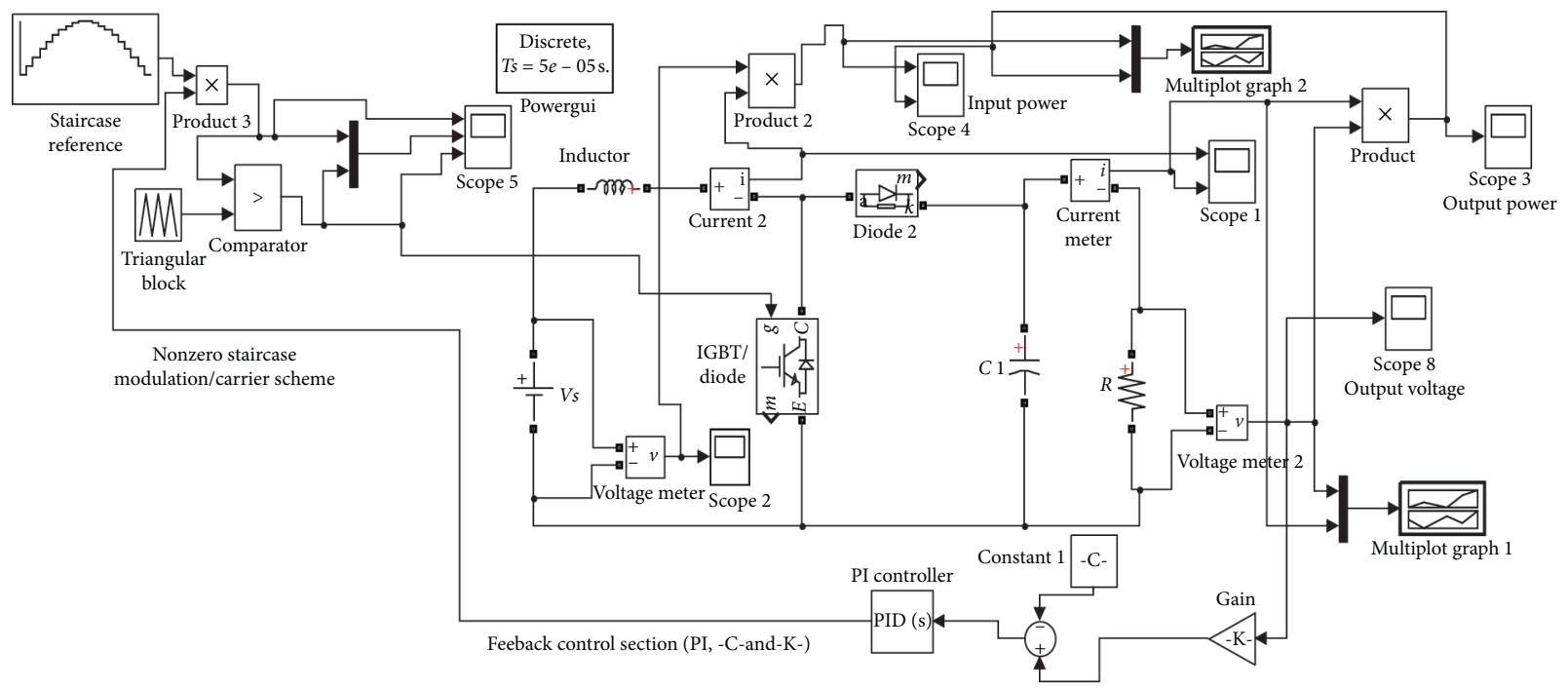

FIgURE 7: MATLAB/simulink model of the proposed system.

TABle 4: Computed values for nonzero staircase modulation scheme.

\begin{tabular}{lccc}
\hline Serial number $(i)$ & $\Theta_{i}\left({ }^{\circ} \mathrm{C}\right)$ & $H_{i}(\mathrm{~m})$ & $h_{i}(\mathrm{~m})$ \\
\hline 1 & 4.50 & 0.78 & 0.73 \\
2 & 13.50 & 2.33 & 2.28 \\
3 & 22.50 & 3.82 & 3.77 \\
4 & 31.50 & 5.22 & 5.17 \\
5 & 40.50 & 6.49 & 6.44 \\
6 & 49.50 & 7.60 & 7.55 \\
7 & 58.50 & 8.53 & 8.03 \\
8 & 67.50 & 9.24 & 9.19 \\
9 & 75.50 & 9.72 & 9.67 \\
10 & 85.50 & 9.97 & 9.92 \\
11 & 85.50 & 9.97 & 9.92 \\
12 & 75.50 & 9.72 & 9.67 \\
13 & 67.50 & 9.24 & 9.19 \\
14 & 58.50 & 8.53 & 8.03 \\
15 & 49.50 & 7.60 & 7.55 \\
16 & 40.50 & 6.49 & 6.44 \\
17 & 31.50 & 5.22 & 5.17 \\
18 & 22.50 & 3.82 & 3.77 \\
19 & 13.50 & 2.33 & 2.28 \\
20 & 4.50 & 0.78 & 0.73 \\
\hline
\end{tabular}

Step F: single click on "FFT analysis;" it will display four subsections: signal section, FFT analysis section, available signal section, and FFT setting section.

Step G: finally, click on the display button; the FFT analysis section, it will show the total harmonic distortion level of the output wave in percentage value and in bar chart form.

\section{Boost DC-DC Converter Power Circuit and Its Efficiency}

The DC-DC boost converter circuit used in this work is shown in Figure 2. It is the power circuit where the nonzero

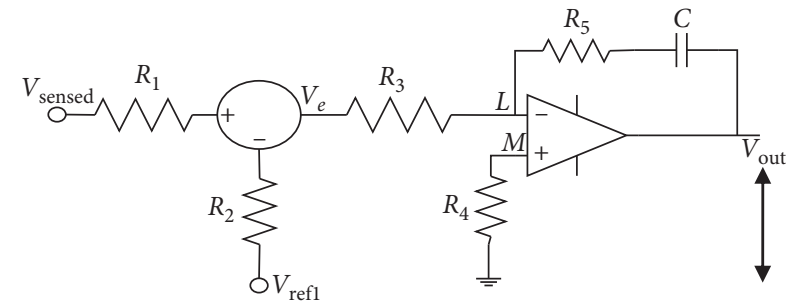

FIgURE 8: Circuit diagram of a proportional-plus-integral controller.

staircase modulation scheme is applied. It operates as follow: during the positive first half cycle, as soon as the power electronics switch, $S_{\mathrm{M}}$ is $\mathrm{ON}$, the fast switching power diode, $D_{\mathrm{m}}$ will switch OFF, and then the magnetic energy flows linearly at the input storage device, $L$. At this moment, load, $R$ depends solely on the electric energy stored in the capacitor, $C$. During the negative half cycle, the switch $S_{M}$ is turned OFF which alternately sets $D_{\mathrm{m}} \mathrm{ON}$. At this point, the already stored magnetic energy in $L$ discharges to charge $C$ to feed the Load. A similar process takes place during other cycles.

Efficiency, $\varepsilon$, of the converter can be defined as the ratio of power output, $P_{\mathrm{o}}$, of the converter to its power input, $P_{s}$, expressed in percent [25].

$$
\varepsilon=\frac{P_{o}}{P_{s}} * 100 .
$$

The parameters used in the power circuit, frequencies, and feedback system of this work are listed in Table 5, while the parameters of the proposed system are shown in Table 4. Table 5 also contains the output power of the DC-DC converter using the proposed modulation scheme.

The MATLAB Simulink block and the control unit of Figure 2 are shown in Figure 7 . Figure 7 consists of the staircase modulation scheme, power circuit, Simulink 
TABle 5: Parameters used in the proposed system.

\begin{tabular}{lc}
\hline Parameter & Ratings \\
\hline Duty cycle and load resistance & 0.90 and $50 \Omega$ \\
Capacitance, $C$ & $780 \mu \mathrm{F}$ \\
Input inductance, $L$ & $3 \mathrm{mH}$ \\
Input and output voltages, vs and $V_{\mathrm{o}}$ & $48 \mathrm{~V}$ and $500 \mathrm{~V}$ \\
Power IGBT switch & $600 \mathrm{~V}, 160 \mathrm{~A}$ \\
Power diode & $1000 \mathrm{~V}$ \\
Switching and reference frequencies & $1.5 \mathrm{kHz}$ and $50 \mathrm{~Hz}$ \\
Proportional and integral values & $1.0 \mathrm{and} 0.57$ \\
Output power & $4591 \mathrm{~W}$ \\
\hline
\end{tabular}

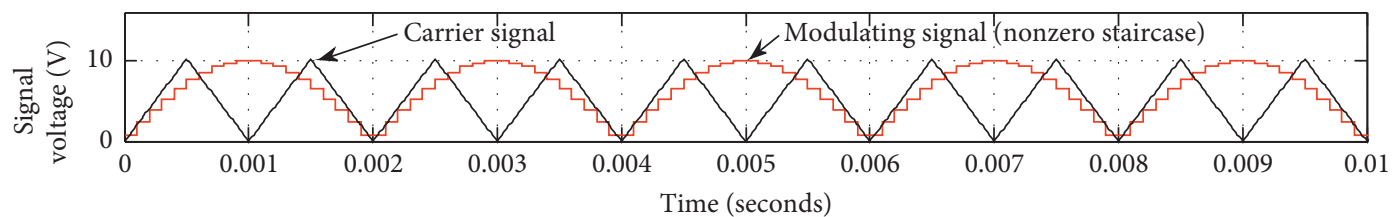

(a)

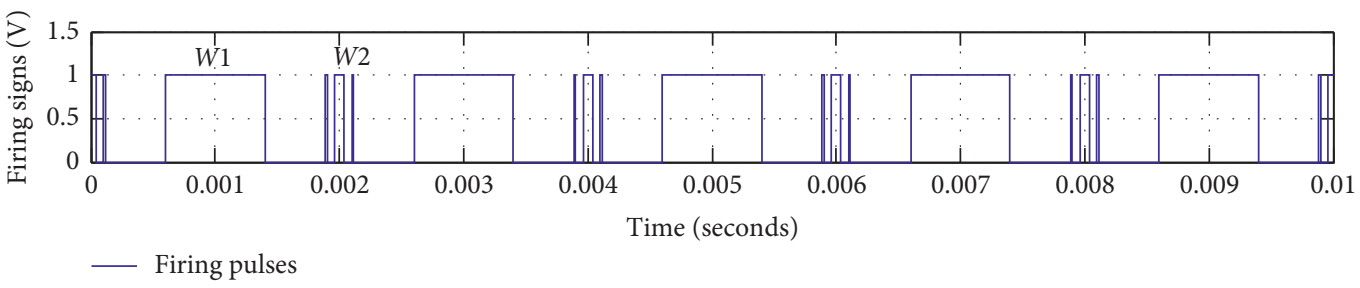

(b)

Figure 9: Nonzero staircase modulation scheme.

measuring blocks, and negative control feedback. The control feedback is made up of voltage sensors, dc-negative reference, and PI controllers.

\section{Simulation Results}

This work was simulated in MATLAB/Simulink 2014 environment. Figure 9(a) shows a comparison of triangular waves (carrier signal), $C_{r}$, with nonzero staircase reference, (NZSR) waveform. It was observed that when NZSR is greater than $C_{r}$, a firing pulse is formed as shown in Figure 9(b). Figure 9(b) displays two distinctive trains of pulses with different pulse widths. The pulse at the position of $W 1$, reduces the low order harmonic distortions, whereas the pulse at the position of W2 in Figure 9(b) mitigates the high order harmonics in the proposed system. The pulses in Figure 9(b) are used to trigger the IGBT switch, $S_{M}$, in Figures 2 and 7 before any output waveform can be produced.

In Figure 10(a), a plot of the source voltage of $48 \mathrm{~V}$ versus time is illustrated, while in Figure 10(b), the current flowing through the inductor, $L$, is displayed. The transient stage of the current occurred at a time duration of $0 \leq t \leq 0.5$ seconds with the highest current value of $150 \mathrm{~A}$. The current waveform later stabilized at $0.5 \leq t \leq 1$ seconds at a currentof 100 A with some ripples.
The output voltage and current versus time of the proposed system are plotted in Figures 10(a) and 10(b) respectively. The results show that oscillations occur in the waveforms between zero (0) seconds and 0.5 seconds until they are stabilized immediately after 0.5 seconds with a voltage and amplitude of $480.3 \mathrm{~V}$ and $9.56 \mathrm{~A}$ respectively.

The characteristic performance of the output voltage and current are illustrated in Figures 11(a) and 11(b). The transient and steady states occurred at $0 \leq t \leq 0.031$ seconds and $0.54 \leq t \leq 1$ seconds.

The power input and output of the DC-DC boost converter of the proposed system are plotted against time in Figures 12(a) and 12(b). In Figure 12(a), at $0 \leq t \leq 0.031 \mathrm{sec}-$ onds, the power input rises to $8000 \mathrm{~W}$ and at $t=0.18$ seconds, it sharply dropped down to $6000 \mathrm{~W}$. Then between 0.0321 seconds and 0.5 seconds, it fluctuates at different ratings due to the unstable state of the system during the transient stage. Beyond 0.5 seconds, the power input is stabilized at $4800 \mathrm{~W}$ throughout the operation. Figure 12(b) shows that during the transient stage, the power output did not drop sharply, rather it reached its peak point $(60015 \mathrm{~W})$ and finally stabilized at $4591 \mathrm{~W}$. The stabilization of the output power and also that of current and voltage were due to the proportional integral (PI) controller incorporated in the system. The results show that under steady state operation of the system, a power loss of $209 \mathrm{~W}$ and an efficiency of $96 \%$ is realized. 


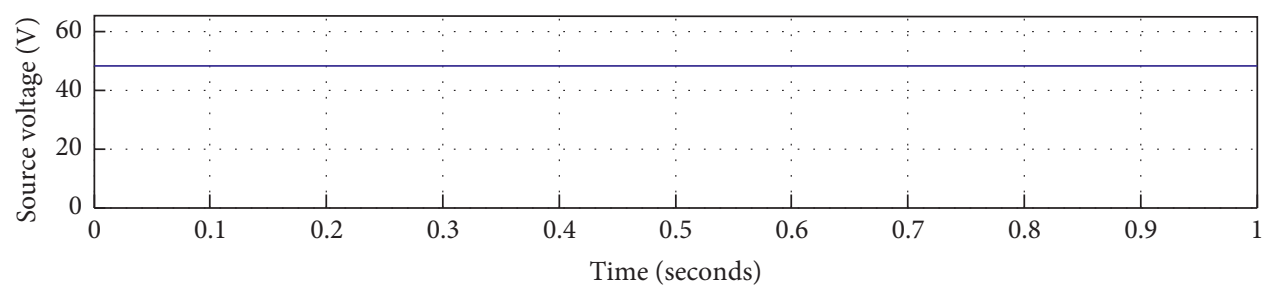

— Battery voltage

(a)

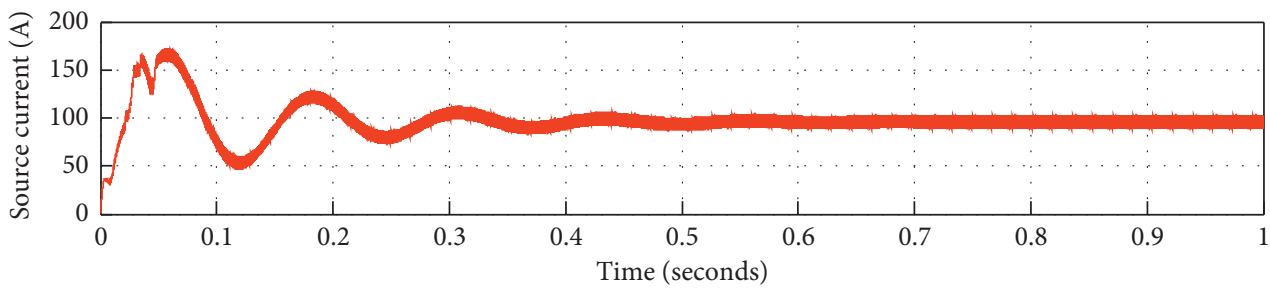

_ Source current through inductor

(b)

FIgURE 10: (a) Source voltage and (b) source current.

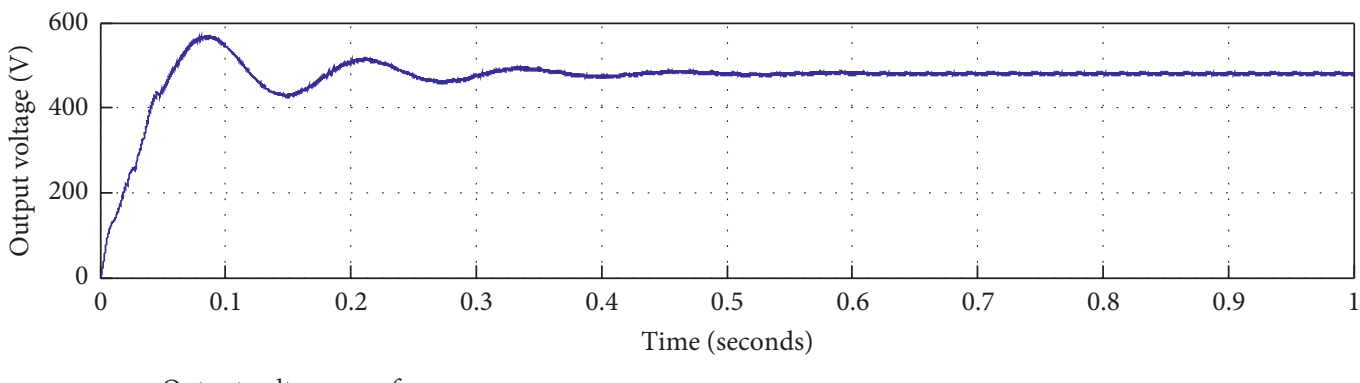

(a)

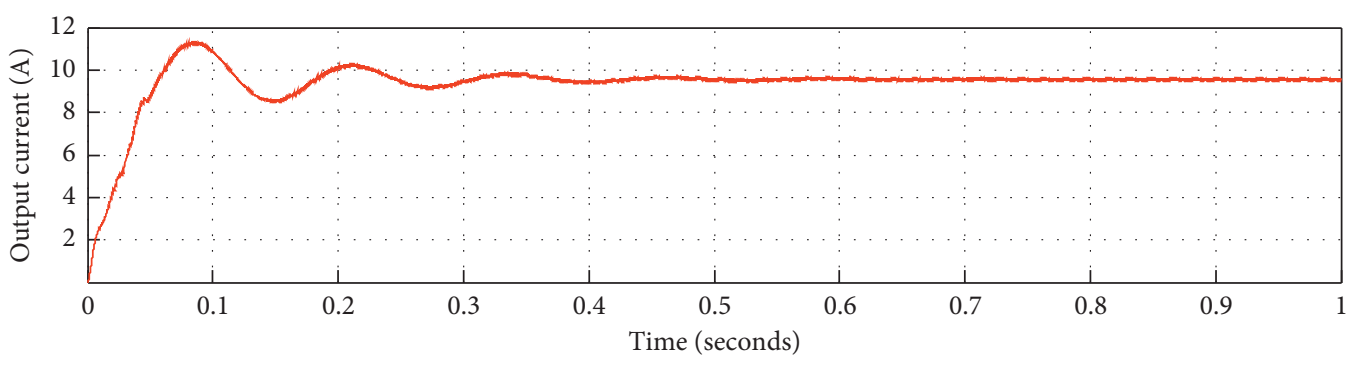

— Output current waveform

(b)

Figure 11: (a) Output voltage versus time and (b) output current versus time.

The spectral analysis of the output voltage realized in this work is portrayed in Figure 13. It is observed from the figure that the THD of the voltage output waveform obtained is $0.56 \%$ at $50 \mathrm{~Hz}$ fundamental frequency of the staircase reference signal.

The spectral analysis of the output power is shown in Figure 14. It can be observed from Figure 14 that the power output is $1.12 \%$ of the THD. This implies that the total current harmonics distortion is equal to $0.56 \%$.

Figure 15 shows the tracking probability of output voltage waveform during transient and steady state on the normal statistical reference judgment. It was observed that during transient state, the output voltage waveform is beyond the judgment line with a probability value of 


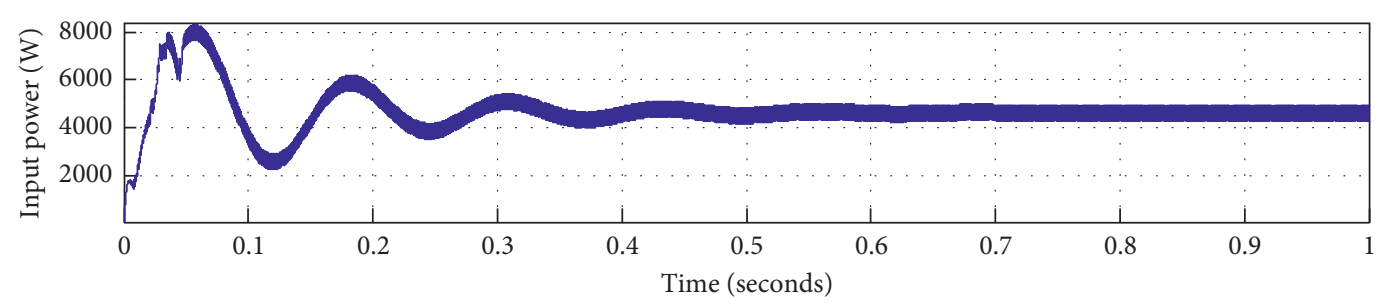

_ Input power waveform

(a)

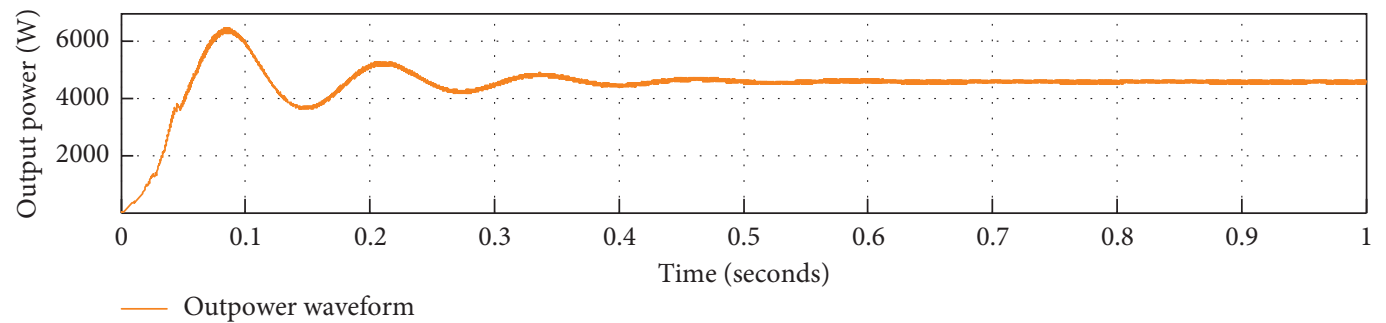

(b)

Figure 12: (a) Input power and (b) output power.

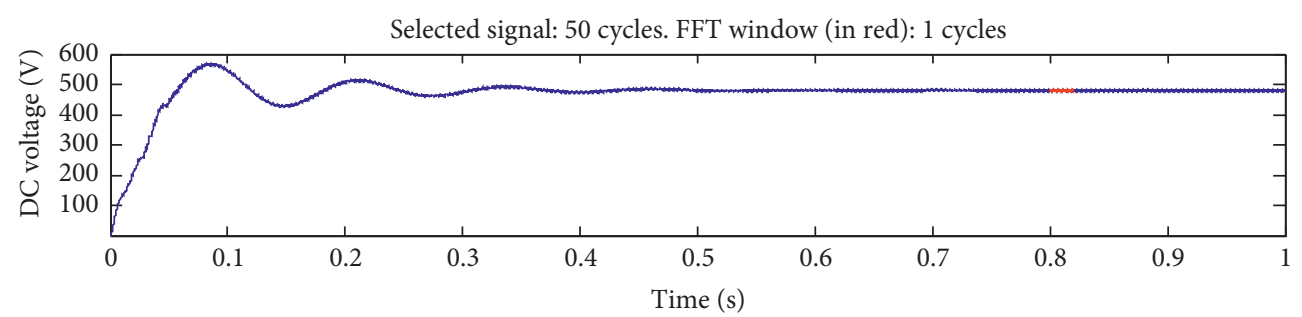

(a)

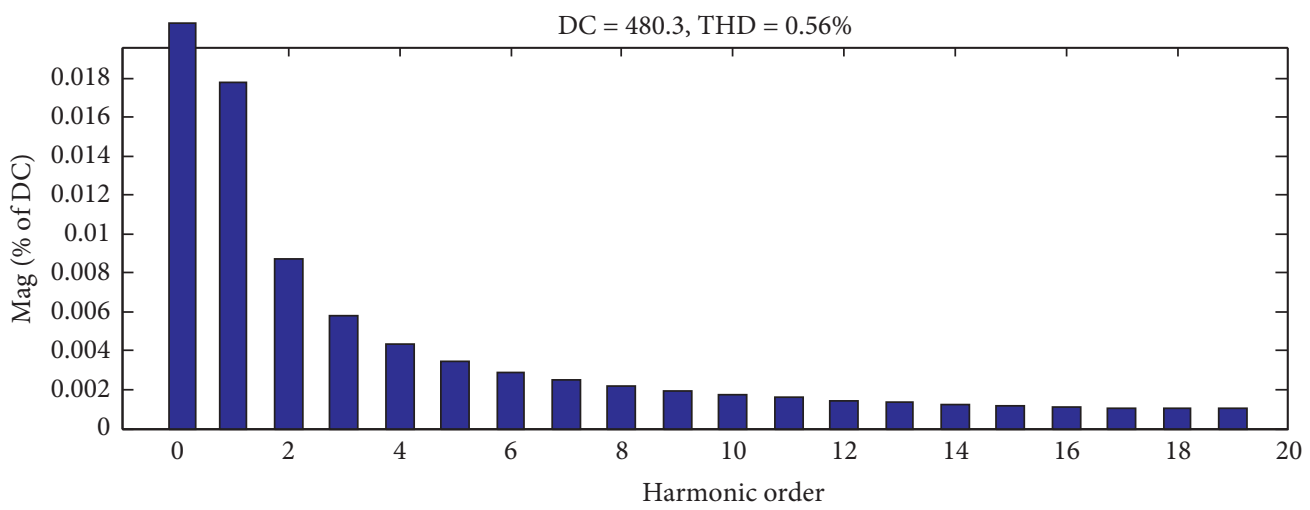

(b)

Figure 13: Spectral analysis of the output voltage.

0.12. This contributes relatively to high loss during the transient state. During the stable state, the probability of tracking is 0.90 . This implies low power loss during the steady state.

A comparative analysis of different modulation schemes such as RTMS, DCVCSM, DCVTBM, and ZPCSMS, with the proposed scheme shown in Figure 2 is presented in
Table 6. The comparison distinguishes the RTMS, DCVCSM, DCVTBM, and ZPCSMS schemes from the proposed scheme with respect to the nature of the firing signals, power input, power output, power losses, and THDs. Using the same criteria for all schemes, it was observed that the proposed scheme exhibits the lowest power loss as well as the highest power output and efficiency. 


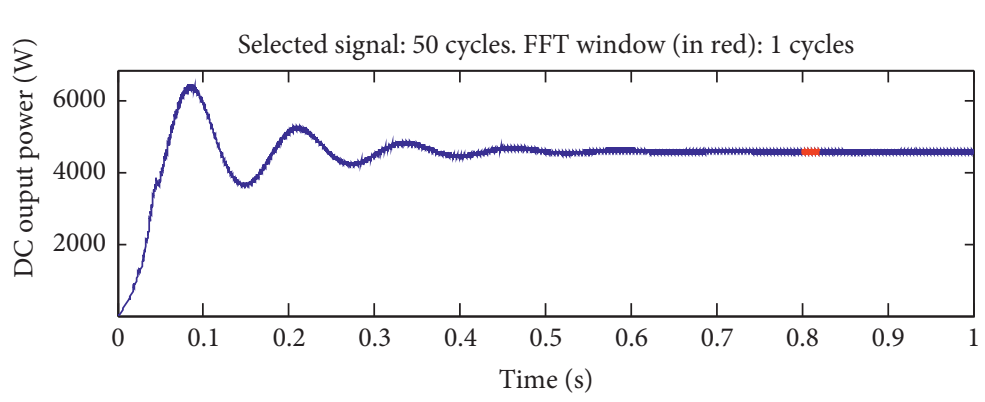

(a)

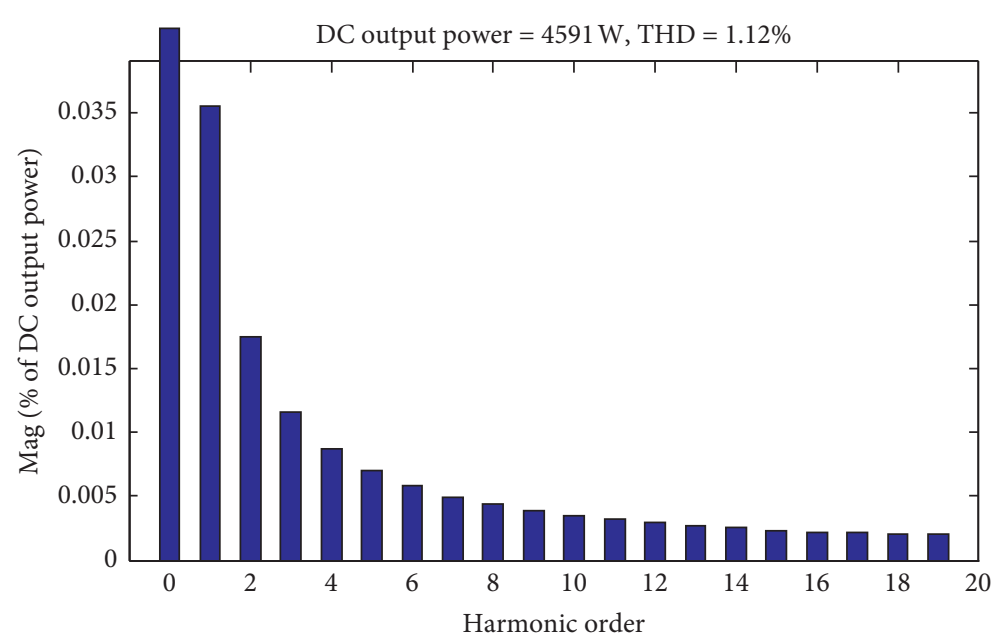

(b)
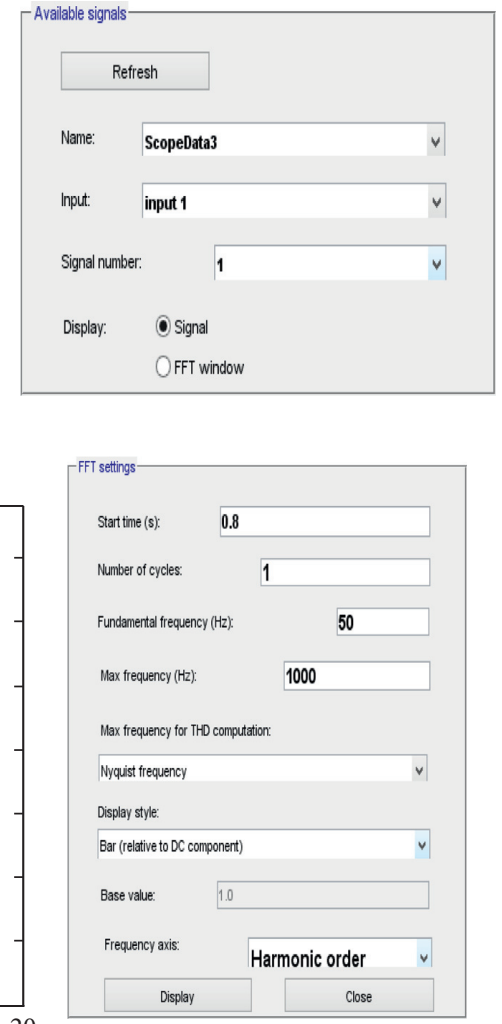

FIGURE 14: Spectral analysis of the output power.

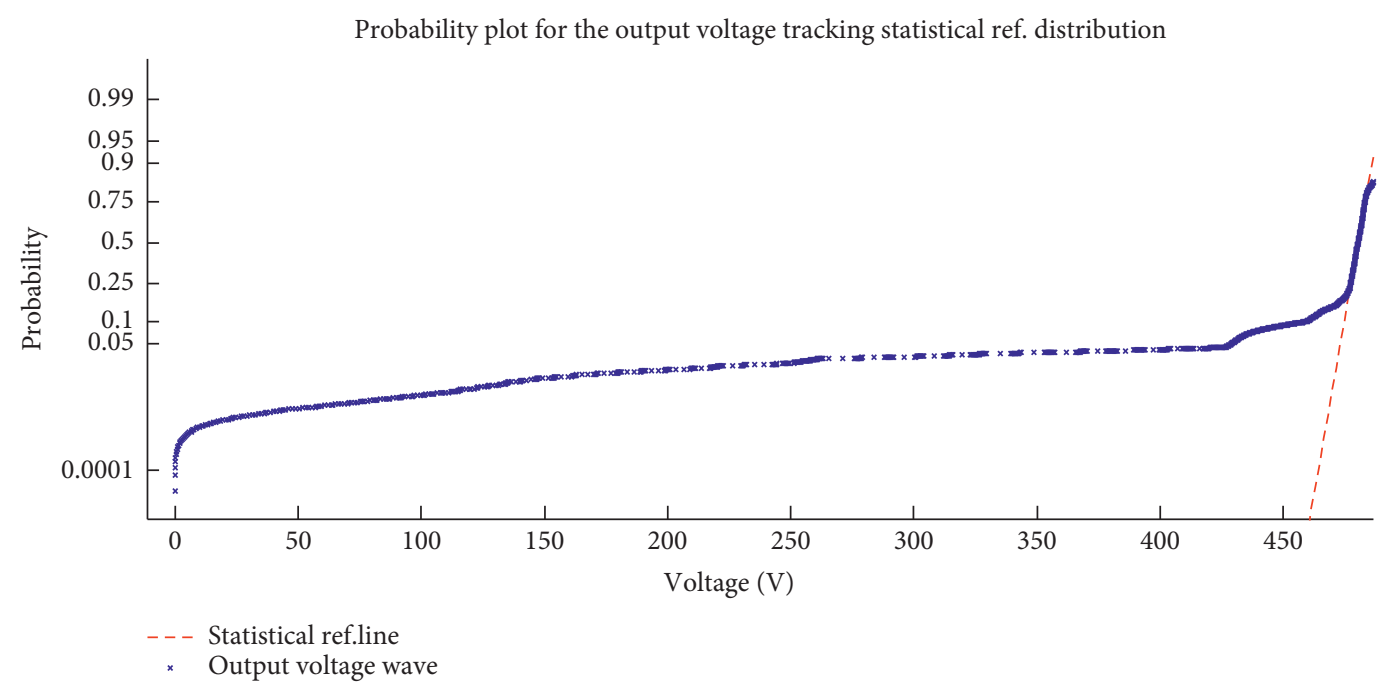

FIgURE 15: Output voltage versus statistical reference line.

Table 6 presents a comparison of conventional modulation schemes with the proposed scheme. The comparative analysis with existing schemes used in single switch boost DC-
DC converters as shown in Figures 1, 3-5 as well as in Table 6, shows that the proposed nonzero staircase modulation scheme performs better than other conventional schemes. 
TABLE 6: Comparative analysis of different modulation schemes.

\begin{tabular}{|c|c|c|c|c|c|}
\hline $\begin{array}{l}\text { Modulation } \\
\text { scheme }\end{array}$ & $\begin{array}{c}\text { Rectified-triangular } \\
\text { modulation scheme } \\
\text { (RTMS) Figures 1(a)- } \\
\text { 1(c) }[13,19]\end{array}$ & $\begin{array}{l}\text { DC voltage compared } \\
\text { with Sawtooth } \\
\text { modulation scheme } \\
\quad(\text { DCVCSM) } \\
\text { Figures } 3(\mathrm{a})-3(\mathrm{c})[12]\end{array}$ & $\begin{array}{l}\text { DC voltage-triangular } \\
\text { based modulation } \\
\text { scheme (DCVTBM) } \\
\text { Figures } 4(\mathrm{a})-4(\mathrm{c}) \\
{[16-18]}\end{array}$ & $\begin{array}{c}\text { Zero potential } \\
\text { compared sinewave } \\
\text { modulation scheme } \\
\text { (ZPCSMS) Figures 5(a)- } \\
\text { 5(c) }[13,17]\end{array}$ & $\begin{array}{l}\text { Nonzero staircase } \\
\text { modulation } \\
\text { scheme (proposed } \\
\text { scheme) }\end{array}$ \\
\hline $\begin{array}{l}\text { Nature of the } \\
\text { firing signals }\end{array}$ & $\begin{array}{l}\text { Irregular trains of } \\
\text { pulses }\end{array}$ & Uniform trains of pulses & $\begin{array}{l}\text { Uniform trains of } \\
\text { pulses }\end{array}$ & Uniform trains of pulses & $\begin{array}{l}\text { Two distinctive } \\
\text { trains of pulses }\end{array}$ \\
\hline $\begin{array}{l}\text { System power } \\
\text { input (W) }\end{array}$ & 4800.00 & 4800.00 & 4800.00 & 4800.00 & 4800.00 \\
\hline $\begin{array}{l}\text { System power } \\
\text { output (W) }\end{array}$ & 2928.00 & 4006.00 & 4204.00 & 2229.00 & 4591.00 \\
\hline $\begin{array}{l}\text { System power } \\
\text { losses (W) }\end{array}$ & 1872.00 & 794.00 & 596.00 & 2571.00 & 209.00 \\
\hline $\begin{array}{l}\text { System } \\
\text { efficiency }\end{array}$ & $66 \%$ & $83 \%$ & $88 \%$ & $46 \%$ & $96 \%$ \\
\hline THD & $9.79 \%$ & $7.89 \%$ & $4.65 \%$ & $33.74 \%$ & $1.12 \%$ \\
\hline
\end{tabular}

Apart from its outstanding performance, the proposed scheme also has a moderate impact during the transient state. Furthermore, we envisage that in real time implementation, it might require large operational amplifiers. This can be improved by using microcontroller-based nonzero staircase modulation schemes for practical purposes. The proposed modulation scheme can be applied in single switch or double switch boost DC-DC converter-based-hospital equipment such as in implantable cardiac pacemaker [26], oxygen concentrators, pulse oximeters, phototherapy device in rural healthcare centers, and ultrasound power supply units [27].

\section{Conclusion}

This paper presented a novel modulation scheme otherwise known as the nonzero staircase modulation scheme for switching single-switched DC-DC boost converter. The proposed scheme possesses the followings properties: power input of $4800 \mathrm{~W}$, power output of $4591 \mathrm{~W}$ with $1.12 \%$ total harmonic distortion (THD), output voltage and current of $480.3 \mathrm{~V}$ and $9.56 \mathrm{~A}$ with $0.56 \%$ THD each, and efficiency of $96 \%$ and power loss of $209 \mathrm{~W}$. The comparative analysis with existing schemes shows that the proposed scheme outperforms other existing modulation schemes.

\section{Data Availability}

All data sources have been appropriately cited within the manuscript.

\section{Conflicts of Interest}

The authors declare that they have no conflicts of interest.

\section{References}

[1] M. Forouzesh, Y. P. Siwakoti, S. A. Gorji, F. Blaabjerg, and B. Lehman, "Step-up DC-DC converters: a comprehensive review of voltage-boosting techniques, topologies, and applications," IEEE Transactions on Power Electronics, vol. 32, no. 12, pp. 9143-9178, 2017.
[2] D. W. Hart, Power Electronics, McGraw-Hill Companies, Inc., New York, NY, USA, 2011.

[3] M. H. Rashid, Power Electronics Circuits, Devices and Application, Prentice Hall of India, Delhi, India, Third edition, 2004.

[4] M. K. Kazimierczuk, Pulse-Width Modulated DC-DC Power Converters, Wiley, Chichester, UK, 2008.

[5] T. G. Wilson, "The evolution of power electronics," IEEE Transactions on Power Electronics, vol. 15, no. 3, pp. 439-446, 2000.

[6] B. Bose, "The past, present, and future of power electronics [Guest Introduction]," IEEE Industrial Electronics Magazine, vol. 3, no. 2, pp. 7-11, 2009.

[7] J. I. Leon, S. Kouro, L. G. Franquelo, J. Rodriguez, and B. Wu, "The essential role and the continuous evolution of modulation techniques for voltage-source inverters in the past, present, and future power electronics," IEEE Transactions on Industrial Electronics, vol. 63, no. 5, pp. 2688-2701, 2016.

[8] K. S. Srinivasu, S. M. Shariff, and K. Satyaanarayana, "Staircase control of hybrid multilevel inverter topology with reduced number of power electronic components," International Journal of Scientific and Engineering Research, vol. 7, pp. 865-872, 2016.

[9] N. R. Klaes and C. M. Ong, "Implementation and study of a digital staircase pulsewidth modulator," in Proceedings of the IEEE Power Electronics Specialists Conference, pp. 128-134, Blacksburg, VA, USA, June 1987.

[10] M. F. Mohammed, A. H. Ahmad, and A. T. Humod, "Efficiency improvement of DC-DC boost converter by parallel switches connection," International Journal of Applied Engineering Research, vol. 13, pp. 7033-7036, 2018.

[11] A. Tomaszuk and A. Krupa, "High efficiency high step-up DC/ DC converters-a review," Bulletin of the Polish Academy of Sciences: Technical Sciences, vol. 59, no. 4, pp. 475-483, 2011.

[12] K. K. Tse, R. W.-M. Ng, H. S.-H. Chung, and S. Y. R. Hui, “An evaluation of the spectral characteristics of switching converters with chaotic carrier-frequency modulation," IEEE Transactions On Industrial Electronics, vol. 50, no. 1, pp. 171-182, 2003.

[13] M. U. Agu, Principles of Power Electronics Circuits, University of Nigeria Press, Enugu, Nigeria, 2019.

[14] R. Puviarasi, "SW-PWM for high power DC-DC boost converter in automotive fuel cell application," International 
Journal of Pure and Applied Mathematics, vol. 119, no. 16, pp. 3903-3913, 2018.

[15] M. K. Kazimierczuk and L. A. Starman, "Dynamic performance of PWM DC-DC boost converter with input voltage feedforward control," IEEE Transactions on Circuits and Systems I: Fundamental Theory and Applications, vol. 46, no. 12 , pp. 1473-1481, 1999.

[16] A. Fernández, J. Sebastián, P. Villegas, M. M. Hernando, and D. G. Lamar, "Dynamic limits of a power-factor preregulator," IEEE Transactions on Industrial Electronics, vol. 52, no. 1, pp. 77-87, 2005.

[17] H. D. Grahame and T. A. Lipo, "Pulse Width Modulation for Power Converters," Principles and Practice, Vol. 18, Wiley, Hoboken, NJ, USA, 2003.

[18] S. B. Santra, K. Bhattacharya, T. Roy Chudhury, and D. Chatterjee, "Generation of pulse width modulation schemes for power electronic converters," in Proceedings of the National Power Systems Conference, pp. 14-20, Tiruchirappalli, India, December 2018.

[19] C. I. Odeh, "Balancing switching losses in three-phase, fivelevel pulse-width modulation switched voltage source inverter using hybrid modulation techniques," Electric Power Components and Systems, vol. 42, pp. 1195-1200, 2014.

[20] J. M. Jacob, "Industrial Control Electronics; Applications and Design”, Prentice-Hall, Upper Saddle River, NJ, USA, 1989.

[21] A. Wahid and A. P. Prasetyo, "A comparative study between $\mathrm{mpc}$ and pi controller to control vacuum distillation unit for producing LVGO, MVGO, and HVGO," IOP Conference Series: Materials Science and Engineering, vol. 334, pp. 1-6, 2018.

[22] D. Chatterjee, "Voltage regulator using pi controller," Technical Report, National Institute of Technology, Tiruchirappalli, India, 2018.

[23] J. C. Basilio and S. R. Matos, "Design of PI and PID controllers with transient performance specification," IEEE Transactions on Education, vol. 45, no. 4, pp. 364-370, 2002.

[24] N. Farokhnia, H. Vadizadeh, S. H. Fathi, and F. Anvariasl, "Calculating the formula of line-voltage THD in multilevel inverter with unequal DC sources," IEEE Transactions on Industrial Electronics, vol. 58, no. 8, pp. 3359-3372, 2011.

[25] C. Eya and M. Agu, "Solar-based boost differential single phase inverter," Nigerian Journal of Technology, vol. 34, no. 1, pp. 164-176, 2015.

[26] M. K. Zaheeruddin and A. K. Sing, "Solar cell based boost converter for implantable cardiac pacemaker," International Journal of Biomedical Engineering and Technology, vol. 12, no. 3, 2016.

[27] H. Graham, T. Duck, D. Peel, R. Izadnegahdar, and C. Duke, "Solar powered healthcare," International Journal of Tuberculosis and Lung Disease, vol. 20, pp. 572-573, 2016. 